\title{
Endoscopic endonasal approach to the lateral orbital apex: case report
}

\author{
Tomasz A. Dziedzic, MD, ${ }^{1}$ Vijay K. Anand, MD, ${ }^{2}$ and Theodore H. Schwartz, MD ${ }^{1-3}$ \\ Departments of ${ }^{1}$ Neurosurgery, ${ }^{2}$ Otolaryngology, and ${ }^{3}$ Neuroscience, Weill Cornell Medical College, NewYork-Presbyterian \\ Hospital, New York, New York

\begin{abstract}
Although the medial and inferior orbital apex are considered safely accessible using the endonasal endoscopic approach, the lateral apex has been considered unsafe to access since the optic nerve lies between the surgeon and the pathology. The authors present the case of a 4-year-old girl with recurrent rhabdomyosarcoma attached to the lateral rectus muscle located lateral and inferior to the optic nerve in the orbital apex. The tumor was totally resected through an endoscopic endonasal transmaxillary transpterygoidal approach using a $45^{\circ}$ endoscope. A gross-total resection was achieved, and the patient's vision was unchanged. This procedure is a safe, minimal-access alternative to open procedures in selected cases and provides evidence that increases the applicability of the endonasal endoscopic approach to reach the lateral compartment of the orbital apex.
\end{abstract}

http://thejns.org/doi/abs//10.3171/2015.2.PEDS1575

KEY WORDS endoscopic; endonasal; orbital apex; rhabdomyosarcoma; optic nerve; skull base; transmaxillary; transpterygoidal; craniofacial

$\mathrm{E}$ NDONASAL endoscopic approaches provide a minimal-access corridor to much of the midline skull base.$^{15}$ Although approaches to the medial orbit are well described, the lateral orbit has been considered offlimits since the approach would have to traverse the plane of the optic nerve as well as the inferior and lateral rectus muscles. ${ }^{1,5,11,13}$ However, using a transmaxillary transpterygoidal corridor, a path inferior to the periorbita of the orbital apex can be used to reach the compartment lateral to the orbital apex..$^{7,8}$ Although feasibility has been provided through cadaver dissection, a clinical case report has not yet been described. Rhabdomyosarcoma is a rare and malignant tumor that mainly affects pediatric patients. These tumors frequently occupy the orbit and arise from undifferentiated cells that have the potential to become striated muscle. ${ }^{6}$ Treatment of these patients involves a combination of surgery, radiotherapy, and chemotherapy. We present the case of a patient who underwent successful total removal of a tumor recurrence, which was located both inferior and lateral to the optic nerve, using an endonasal endoscopic approach.

\section{Case Report}

History

A 4-year-old right-handed girl was diagnosed with a swollen right eye and proptosis that had persisted for 16 months. MRI revealed a lesion within the medial orbital cavity that was hypointense on T1- and T2-weighted images; diffusion restriction and contrast enhancement were also observed. At the time of the diagnosis the patient underwent tumor biopsy through an orbital incision. Pathological examination demonstrated an embryonal subtype of rhabdomyosarcoma. The patient was treated with chemotherapy (24 weeks) and radiotherapy (5 weeks). After 6 months the patient was in remission. MRI performed a year after the diagnosis showed a local recurrence inferior to the orbital apex. She was treated with chemotherapy again and was referred for endoscopic endonasal transmaxillary transpterygoidal tumor resection. Pathology demonstrated fibrous scar tissue, sparse chronic inflammatory cells, and peripheral nerve elements with no tumor tissue despite radiographic gross-total resection. After 2 
months, continuous tumor growth was observed with tumor now lateral to the optic nerve and orbital apex, which appeared to be attached to the lateral rectus muscle (Fig. 1). It was unclear why the original pathology was negative for tumor and why the postoperative scan looked clean given this new rapid recurrence. The patient was again referred for endoscopic endonasal resection.

\section{Operative Procedure}

Endonasal endoscopic surgery was performed using frameless stereotactic equipment as previously described.$^{15}$ A bilateral approach with posterior septectomy was performed. A $30^{\circ}$ scope was placed on a scope holder and bimanual surgery was performed. Ethmoidectomy, antrostomy, wide opening of the maxillary sinus, drilling of the perpendicular plate of the pterygoid bone, and removal of the roof of the maxillary sinus/floor of the orbit up to the infraorbital nerve and artery were performed (Fig. 2). A schematic illustration showing the approach is presented in Fig. 3. The periorbita was opened and the tumor was identified. The tumor inferior to the orbital apex was removed, thus creating a corridor into the lateral orbital apex compartment. The periorbita was opened. With a handheld $45^{\circ}$ endoscope, dissection was carried out around the orbital apex to the lateral aspect of the lateral rectus muscle. The tumor was removed along with fibers from the lateral rectus to which it was attached (Fig. 2).
Although orbital fat was identified, the optic nerve was never seen (Video 1).

VIDEO 1. Endoscopic endonasal transmaxillary transpterygoidal approach to the tumor located in the lateral orbital apex. Copyright Theodore Schwartz. Published with permission. Click here to view with Media Player. Click here to view with Quicktime.

\section{Postoperative Course}

The patient was discharged a day after the procedure without neurological deficit. Postoperative MRI revealed gross-total resection (Fig. 1). Final pathology demonstrated recurrent rhabdomyosarcoma.

\section{Discussion}

In this paper we describe the first successful endonasal endoscopic approach to the lateral orbital apex in a patient. Although approaches to the medial orbit are well described, the lateral orbit has been considered off-limits since the approach would have to traverse the plane of the optic nerve as well as the inferior and lateral rectus muscles. ${ }^{1,5,11,13}$ The endonasal approach to the lateral orbit has been described in a single cadaver study. Here, we describe the first case performed in a living patient. ${ }^{8}$

The choice of surgical approach to the orbit is generally determined by location, extension, and the type of lesion. As a rule, cosmetics and accessibility are both con-
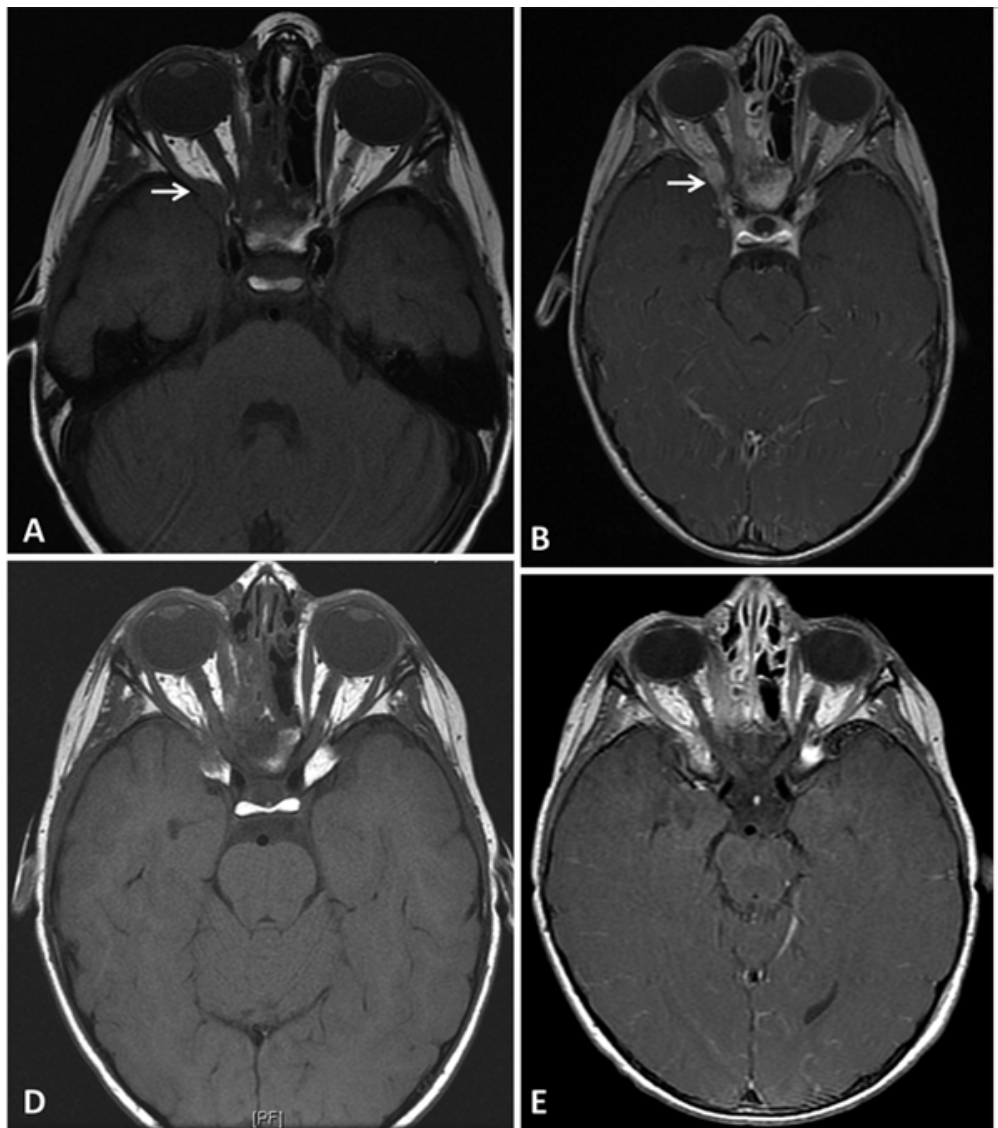
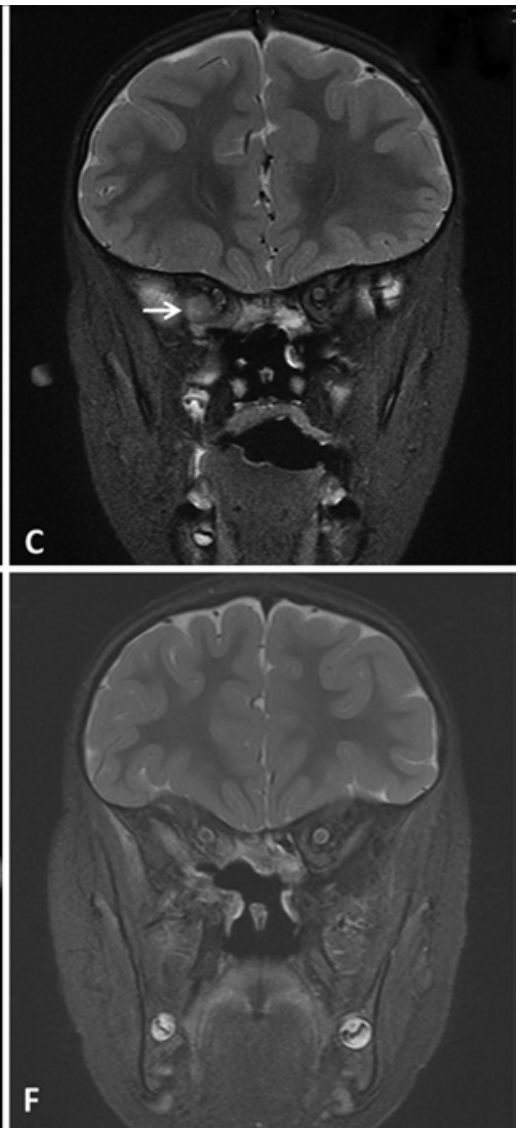

FIG. 1. A-C: Serial preoperative MR images. The arrows indicate the tumor, located lateral to the optic nerve. D-F: Serial postoperative MR images. Axial T1-weighted images ( $A$ and $D)$, postcontrast axial T1-weighted images (B and $E)$, and fat-saturated coronal T2-weighted images ( $\mathrm{C}$ and $\mathrm{F})$. 

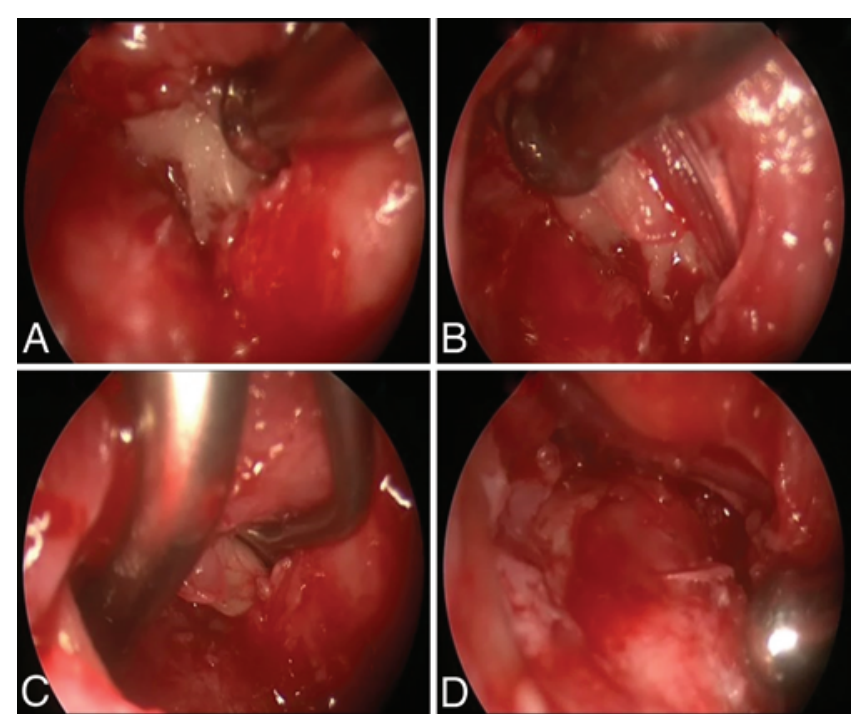

FIG. 2. Intraoperative endoscopic views. A: The tumor in the lateral orbital apex compartment. B: Location of the tumor in relation to the lateral rectus muscle. C: The tumor was removed along with fibers from the lateral rectus to which it was attached. D: View after complete resection of the tumor. Figure is available in color online only.

sidered. The open surgical approaches have been divided into transorbital or extraorbital. Lesions that are located in the anterior two-thirds of the orbit are usually managed with a transorbital approach and those located in the posterior one-third with an extraorbital approach., ${ }^{3,4}$ More commonly, the endoscopic endonasal approaches have been complementary to the transcranial approaches to the orbit..$^{13}$ Endoscopic orbit surgery began in 1990 with the first series of patients who underwent successful decompression for Grave's orbitopathy. ${ }^{2}$

Since then, the endoscopic approaches have expanded to include the removal of pathology in the medial and inferior orbit. $1,5,11,13$ Access is provided by incorporating removal of the perpendicular plate of the pterygoid bone and opening the superior wall of the maxillary sinus.? However, until recently, these approaches were considered only suitable for pathology in the medial and inferior orbit since reaching the lateral orbit would require transgression of the inferior rectus muscle and optic nerve. In the literature there are anatomical descriptions of approaches in cadavers to the orbit with visualization of the space lateral to the optic nerve. ${ }^{8,14}$ According to the authors, this approach can be safely used only in patients who have lost their vision because of the high risk of optic nerve damage. ${ }^{8}$ The patient described in this report had no problems with vision or eye movements before surgery and no new deficits after surgery. In the paper by Kenyon and Antisdel, the authors described an endoscopic approach to the lateral orbital apex in a cadaver. ${ }^{8}$ However, they described this approach as "transorbital," which implies that the orbit was transgressed. In our case report, we reached the lateral orbit by passing under the orbital apex through a corridor created by removing the roof of the maxillary sinus as well as by the tumor itself, which extended inferior to the orbit.

Rhabdomyosarcoma comprises 4 main histological subtypes, and it is important to distinguish them for treatment and prognosis. These 4 variants are embryonal, botyroid, alveolar, and pleomorphic. The embryonal subtype, which was present in our case, is the most common one, especially in the head and neck area. ${ }^{6}$ Biopsy is an
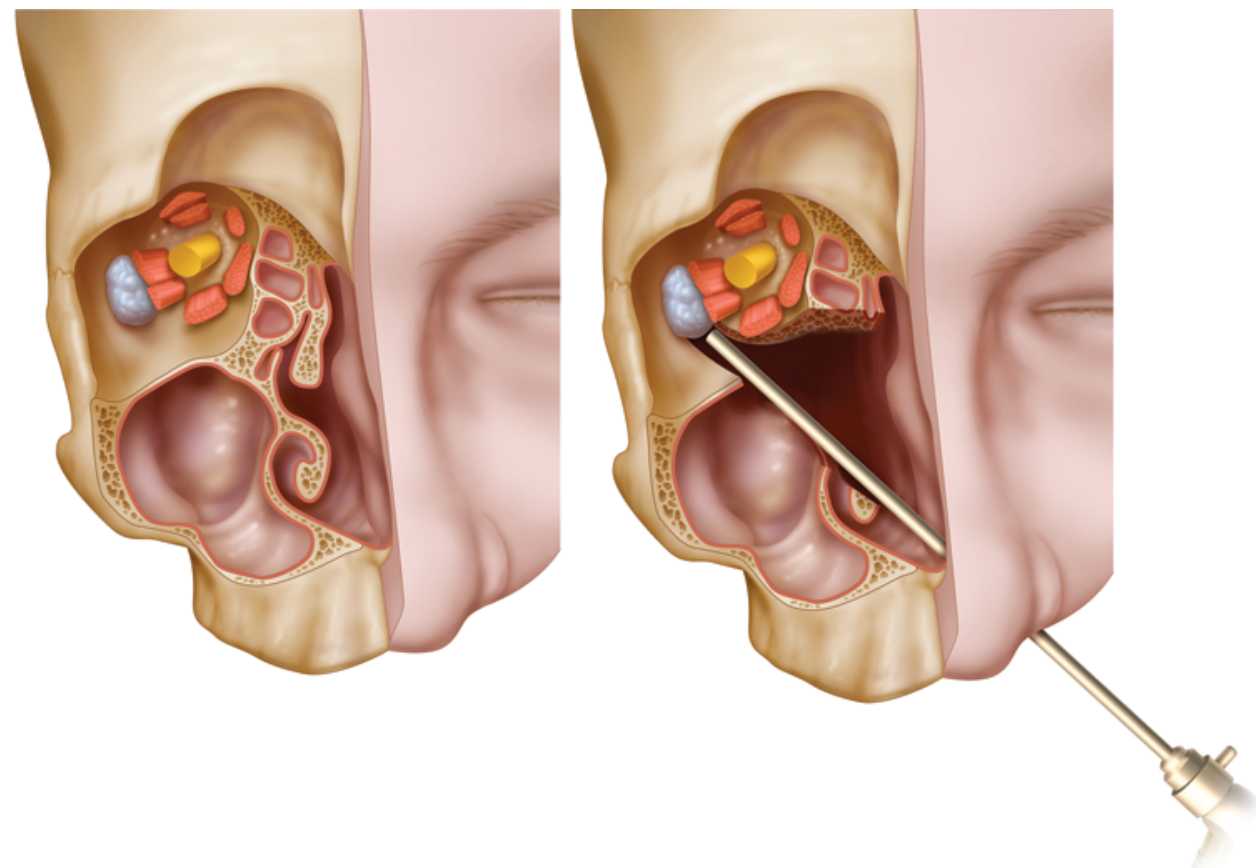

FIG. 3. Left: Schematic illustration showing anatomical relationship between the paranasal sinuses and the tumor located in the lateral compartment of the orbit. Right: Schematic illustration of the endonasal transmaxillary transpterygoidal approach that was used for the tumor removal. Copyright Theodore Schwartz. Published with permission. Figure is available in color online only. 
initial step to be taken when it is suspected that a diagnosis of rhabdomyosarcoma will be confirmed by pathology. According to some authors, the extent of surgical tumor removal plays an important role in survival time. In the cases in which the tumors involve the orbit, only biopsy of the tumor with adjuvant therapy is generally recommended because of the relatively high risk of functional or cosmetic disability. Chemotherapy and radiotherapy are both used as an adjuvant therapy after surgical treatment. ${ }^{17}$

Our patient had the 2 most common symptoms of rhabdomyosarcoma when located in the orbit. The most common symptoms, present in almost all cases, include proptosis followed by globe displacement (usually downward and lateral-apart from the tumor), ptosis, conjunctival swelling, eyelid swelling, or pain. ${ }^{16}$ If tumors are located in the posterior compartment, optic disc edema and choroidal folds may be found on ophthalmological examination. Neurological examination may reveal abrupt eyeball movements and diplopia. ${ }^{17}$

In the literature there are 2 case reports of endoscopic removal of rhabdomyosarcoma located in the orbit. In those 2 cases the tumor was located primarily in the paranasal sinuses with extension into the medial compartment of the orbit. ${ }^{910}$ So far only lesions located medial to the optic nerve have been approached endonasally. ${ }^{5,11,12,18} \mathrm{We}$ describe the first case of an endoscopic endonasal transmaxillary, transpterygoidal approach to remove a tumor located lateral to the optic nerve in the orbital apex. Given that the endonasal endoscopic approach reaches the orbit from an inferior and medial trajectory, the ability to expose the lateral orbit is only appropriate for small and preferably soft tumors. Although follow-up in our case is limited to only 3 months, there has been no recurrence, and, given the rapidity of the first recurrence, this is encouraging. The endonasal endoscopic approach should be considered for selected cases as one way to reach pathology in the lateral orbital apex.

\section{References}

1. Abuzayed B, Tanriover N, Gazioglu N, Eraslan BS, Akar Z: Endoscopic endonasal approach to the orbital apex and medial orbital wall: anatomic study and clinical applications. J Craniofac Surg 20:1594-1600, 2009

2. Antisdel JL, Gumber D, Holmes J, Sindwani R: Management of sinonasal complications after endoscopic orbital decompression for Graves' orbitopathy. Laryngoscope 123:20942098, 2013

3. Bejjani GK, Cockerham KP, Kennerdel JS, Maroon JC: A reappraisal of surgery for orbital tumors. Part I: extraorbital approaches. Neurosurg Focus 10(5):E2, 2001

4. Cockerham KP, Bejjani GK, Kennerdell JS, Maroon JC: Surgery for orbital tumors. Part II: transorbital approaches. Neurosurg Focus 10(5):E3, 2001

5. Düz B, Secer HI, Gonul E: Endoscopic approaches to the orbit: a cadaveric study. Minim Invasive Neurosurg 52:107-113, 2009

6. Hayes-Jordan A, Andrassy R: Rhabdomyosarcoma in children. Curr Opin Pediatr 21:373-378, 2009

7. Hofstetter CP, Singh A, Anand VK, Kacker A, Schwartz TH: The endoscopic, endonasal, transmaxillary transpterygoid approach to the pterygopalatine fossa, infratemporal fossa, petrous apex, and the Meckel cave. J Neurosurg 113:967974, 2010

8. Kenyon B, Antisdel JL: Anatomic evaluation of endoscopic transnasal transorbital approach to the lateral orbital apex. Am J Rhinol Allergy 28:82-85, 2014

9. Luu QC, Lasky JL, Moore TB, Nelson S, Wang MB: Treatment of embryonal rhabdomyosarcoma of the sinus and orbit with chemotherapy, radiation, and endoscopic surgery. J Pediatr Surg 41:e15-e17, 2006

10. Moon HS, Kwon SW, Lee JH: A case of alveolar rhabdomyosarcoma of the ethmoid sinus invading the orbit in an adult. Korean J Ophthalmol 20:70-75, 2006

11. Muscatello L, Seccia V, Caniglia M, Sellari-Franceschini S, Lenzi R: Transnasal endoscopic surgery for selected orbital cavernous hemangiomas: our preliminary experience. Head Neck 35:E218-E220, 2013

12. Netuka D, Masopust V, Belšán T, Profantová N, Beneš V: Endoscopic endonasal resection of medial orbital lesions with intraoperative MRI. Acta Neurochir (Wien) 155:455-461, 2013

13. Roth J, Fraser JF, Singh A, Bernardo A, Anand VK, Schwartz TH: Surgical approaches to the orbital apex: comparison of endoscopic endonasal and transcranial approaches using a novel 3D endoscope. Orbit 30:43-48, 2011

14. Schultheiß S, Petridis AK, El Habony R, Maurer P, Scholz M: The transmaxillary endoscopic approach to the orbit. Acta Neurochir (Wien) 155:87-97, 2013

15. Schwartz TH, Fraser JF, Brown S, Tabaee A, Kacker A, Anand VK: Endoscopic cranial base surgery: classification of operative approaches. Neurosurgery 62:991-1005, 2008

16. Shields CL, Shields JA, Honavar SG, Demirci H: Clinical spectrum of primary ophthalmic rhabdomyosarcoma. Ophthalmology 108:2284-2292, 2001

17. Shields JA, Shields CL: Rhabdomyosarcoma: review for the ophthalmologist. Surv Ophthalmol 48:39-57, 2003

18. Yoshimura K, Kubo S, Yoneda H, Hasegawa H, Tominaga $\mathrm{S}$, Yoshimine T: Removal of a cavernous hemangioma in the orbital apex via the endoscopic transnasal approach: a case report. Minim Invasive Neurosurg 53:77-79, 2010

\section{Author Contributions}

Conception and design: all authors. Acquisition of data: all authors. Analysis and interpretation of data: all authors. Drafting the article: all authors. Critically revising the article: Schwartz. Reviewed submitted version of manuscript: Schwartz, Anand. Approved the final version of the manuscript on behalf of all authors: Schwartz. Study supervision: Schwartz.

\section{Supplemental Information Videos}

Video 1, Media Player. http://mfile.akamai.com/21490/wmv/ digitalwbc.download.akamai.com/21492/wm.digitalsource-naregional/peds15-75_video_1.asx.

Video 1, Quicktime. http://mfile.akamai.com/21488/mov/ digitalwbc.download.akamai.com/21492/qt.digitalsource-global/ peds15-75_video_1.mov.

\section{Correspondence}

Theodore H. Schwartz, Department of Neurosurgery, Weill Cornell Medical College, NewYork-Presbyterian Hospital, 525 E. 68th St., Box \#99, New York, NY 10065. email: schwarh@med. cornell.edu. 